\title{
Weatherability of Arc Thermal Spray Al-Mg Coating in a Simulated Marine Environment
}

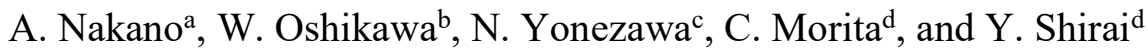 \\ ${ }^{\text {a }}$ Center for Collaborative Research \& Community Cooperation, University of Miyazaki, \\ Miyazaki 889-2192, Japan \\ ${ }^{\mathrm{b}}$ Faculty of Engineering, University of the Ryukyus, Okinawa 903-0129, Japan \\ ${ }^{\mathrm{c}}$ DAIHEN Corporation, Osaka 532-8512, Japan \\ d Faculty of Engineering, University of Miyazaki, Miyazaki 889-2192, Japan
}

\begin{abstract}
Anticorrosion property of Al-5mass $\% \mathrm{Mg}$ sprayed coating was evaluated by an atmospheric exposure test simulating marine environment for one-year. The test simulating marine environment means an accelerated exposure test where artificial seawater is sprayed on the coating surface in a general atmospheric exposure test. When the initial film thickness is small, the thickness of Al-Mg thermal spray coating decreased. For both exposure tests for oneyear, the corrosion products of Al-Mg thermal spray could not be identified. From the results of EPMA, after the one-year atmospheric exposure test, $\mathrm{Cl}$ originating from airborne salts in atmosphere or from sprayed artificial seawater was not observed in the surface or inside of the Al-Mg coating. The spontaneous potential of Al-Mg thermal spray coating shifted to the noble side from that of the initial material after the one-year atmospheric exposure test. The anode polarization exhibited the same behavior in the two kinds of atmospheric exposure tests.
\end{abstract}

\section{Introduction}

Surface modification technology such as chemical conversion coating, anodic oxidation, and metal coating is one of the effective anticorrosion measures that can extend lifetimes and functions of small machine parts and large steel structures, because corrosion resistance and wear resistance can be drastically improved by protecting the base material surface (1-7). Recently, from the viewpoint of life cycle cost reduction, thermal spray coating has been widely used for anticorrosion of infrastructures, such as highways, bridges, pipelines, and pole transformers with complex shape (8-11). For long-time anticorrosion of large structures in marine environment, arc spraying technology is effectively applied as cathodic protection methods using sacrificial anodes (12). In these methods, metals such as $\mathrm{Al}, \mathrm{Zn}, \mathrm{Al}-\mathrm{Zn}$ alloys, and $\mathrm{Al}-\mathrm{Mg}$ alloys are mainly used as materials (13-15).

Studies of weather resistance of thermal spray coating have clarified that the coatings by $\mathrm{Al}$, high-Al content $\mathrm{Zn}-\mathrm{Al}$ alloys, or high-Al content $\mathrm{Al}-\mathrm{Mg}$ alloys have long-time high corrosion resistance. As a result of accelerated tests using combined cyclic corrosion tests, it was reported that a $\mathrm{Zn}$-coated steel sheet that had been considered to be durable for 25 years in air lost its anticorrosion function by only a 1000-hr combined cyclic corrosion test (16). Also, fluorine-based heavy-duty anticorrosion coating, Al sprayed steel, and Al-Zn 
sprayed steel rusted before the elapse of 4500 hours in combined cyclic tests. On the other hand, it was reported that Al-Mg sprayed steel did not rust even after $9000 \mathrm{hrs}$. Furthermore, in the cross-cut area of Al-Mg sprayed steel, a sacrificial anticorrosion function was appropriately expressed by the white precipitation of Al-Mg alloy (16). In accelerated tests such as combined cyclic corrosion test, we can test corrosion of high corrosion resistance materials in a short time and can evaluate their corrosion resistance. However, it was reported that the forms of corrosion products by an atmospheric exposure test are considerably different from those by an accelerated test (17). Therefore, the relation between these tests are questionable at present.

In the present study, anticorrosion property of $\mathrm{Al}-5 \mathrm{mass} \% \mathrm{Mg}$ sprayed coating was evaluated by an atmospheric exposure test simulating marine environment. Here, the test simulating marine environment means an accelerated exposure test where artificial seawater is sprayed on the coating surface in a general atmospheric exposure test. The resistance to atmospheric corrosion for Al-Mg thermal sprayed steels, which was obtained by one-year atmospheric exposure test simulating marine environment, was evaluated by surface observation, cross-section analysis, and electrochemical tests, based on the comparison with general atmospheric exposure tests.

\section{Experimental}

Atmospheric exposure test simulating marine environment

The atmospheric exposure test simulating marine environment was performed on an exposure footstool, whose exposed area was set up at the horizontal angle of 35 degrees southward in the exposure test field at Okinawa prefecture in Japan. The exposure test was carried out for one-year. The artificial seawater used was the one for metal corrosion test that was in conformity with ASTM D1141. Chemical composition of the artificial seawater in this study is shown in Table 1 . The $20 \mathrm{~L}$ of artificial seawater was made by mixing test powder for metal corrosion that is a chloride component shown in Table 1 with distilled water. The applied amount of the artificial seawater was $2.3 \times 10^{-3} \mathrm{~L}$. By manually applying the artificial seawater with brush on the surface of the specimens every 24 hours, and the influence of chloride on the corrosion was promoted compared to the general atmospheric exposure test. In addition, the general atmospheric exposure test was also carried out about the same time.

Table 1 Chemical composition of the artificial seawater $(\mathrm{g} / \mathrm{L})$

\begin{tabular}{cc|cc}
\hline $\mathrm{NaCl}$ & 24.53 & $\mathrm{NaHCO}_{3}$ & 0.20 \\
$\mathrm{MgCl} \cdot 6 \mathrm{H}_{2} \mathrm{O}$ & 11.11 & $\mathrm{KBr}$ & 0.10 \\
$\mathrm{Na}_{2} \mathrm{SO}_{4}$ (anhydrous) & 4.09 & $\mathrm{SrCl}_{2} \cdot 6 \mathrm{H}_{2} \mathrm{O}$ & 0.04 \\
$\mathrm{CaCl}_{2}$ (anhydrous) & 1.16 & $\mathrm{H}_{3} \mathrm{BO}_{3}$ & 0.03 \\
$\mathrm{KCl}$ & 0.70 & $\mathrm{NaF}$ & 0.003 \\
\hline
\end{tabular}

\section{$\underline{\text { Materials }}$}

Properties of the tested materials in this study is shown in Table 2 . The thermallysprayed steel was prepared by thermally spraying a steel sheet $(150 \times 70 \times 2.3 \mathrm{~mm})$, whose surface had been roughly formed by abrasive blasting, by the electric arc thermally-sprayed with pressurized air. The film thickness of arc thermally-sprayed was used at 4 standards 
Table 2 Properties of the tested materials

\begin{tabular}{ccccc}
\hline \multirow{2}{*}{ Materials } & Coating method & Mrak on the specimens & Thickness $(\mu \mathrm{m})$ & Exposure period (year) \\
\hline \multirow{3}{*}{ Al-5wt\%Mg } & & AlMg30 & 30 & \\
& Electric arc & AlMg60 & 60 & 1 \\
& spraying & AlMg90 & 90 & \\
& & AlMg175 & 175 & \\
\hline
\end{tabular}

Table 3 Deposition parameters of the electric arc spraying process

\begin{tabular}{ccccc}
\hline Air pressure & Spraying Voltage & Spraying Current & Spraying distance & Wire feed rate \\
\hline $0.5-1.0 \mathrm{Mpa}$ & $28 \mathrm{~V}$ & $170 \mathrm{~A}$ & $30 \mathrm{~cm}$ & $11 \mathrm{~m} / \mathrm{min}$ \\
\hline
\end{tabular}

for $30,60,90$ and $150 \mu \mathrm{m}$, the composition of the thermal sprayed coating was Al$5 \mathrm{mass} \% \mathrm{Mg}$. Sealing treatment on the thermal spray coating was not performed. The spray parameters employed were listed in Table 3.

\section{Surface appearance and film thickness measurement}

Surface analysis was carried out with appearance observation and X-ray diffraction to identify corrosion products. The thicknesses of the coating before and after the atmospheric field test were measured using a digital microscope (VHZ100UR, KEYENCE). Specimens for cross-section analysis were cut into $20 \times 20 \mathrm{~mm}$ pieces, vertically buried in epoxy resin. The thickness was measured at 20 locations in total with $1 \mathrm{~mm}$ equal intervals, and the average value of those measurement was assumed to be mean film thickness.

Elemental map at cross-section of a specimen covered with arc thermal spray coating

To analyze the elemental mapping of the arc spray coating before and after the atmospheric field test, cross-section was examined with scanning electron microscope (SEM) observation, and element distribution was analyzed with an electron probe microanalyzer (EPMA, JOEL JAX-8230). Acceleration voltage was $15 \mathrm{kV}$, and magnification was $300 \%$. The distribution of $\mathrm{Mg}(\mathrm{K} \alpha), \mathrm{Al}(\mathrm{K} \alpha), \mathrm{O}(\mathrm{K} \alpha), \mathrm{Cl}(\mathrm{K} \alpha)$, and $\mathrm{S}(\mathrm{K} \alpha)$ was examined.

\section{Electrochemical test}

In order to investigate the polarization properties of $\mathrm{Al}-\mathrm{Mg}$ sprayed steels before and after the atmospheric exposure test, anode/cathode polarization tests were conducted. Artificial seawater was used for the test solution, and the test was conducted by a potentiodynamic method at a potential sweep rate of $10 \mathrm{mV} / \mathrm{min}$. The specimens were put in an electrolytic cell that was set at the predetermined condition for $20 \mathrm{~min}$. Then, after measuring the spontaneous potential, the polarization test was conducted. 
Table 2 Deposition parameters of the arc spraying process

\begin{tabular}{ccccc}
\hline Air pressure & Spraying Voltage & Spraying Current & Spraying distance & Wire feed rate \\
\hline $0.5-1.0 \mathrm{Mpa}$ & $15-30 \mathrm{~V}$ & $100-400 \mathrm{~A}$ & $10-50 \mathrm{~cm}$ & $10-50 \mathrm{~m} / \mathrm{min}$ \\
\hline
\end{tabular}

\section{Results and Discussion}

Corrosion behavior of AlMg thermal spray coating exposed using atmospheric exposure test simulating marine environment

Figure 1 shows the surface appearance of thermal spray coating Al-Mg exposed in the atmospheric exposure test simulating marine environment for one-year. In one-year atmospheric exposure test, it was found that red rust was formed at the edge of the AlMg30 test sample. In the atmospheric exposure test simulating marine environment, red rust was formed in the center of the specimen in the exposure time of two months. After one-year exposure, the red rust spread throughout the surface of specimen. When the coating became thick, as in the cases of AlMg60, AlMg90, and AlMg175, no significant change was observed compared to the initial material. In the case of $\mathrm{AlMg} 30$, steel substrate was exposed in some parts of the thermal spray coating on the initial material. The reason for observing exposure of the steel substrate seems to be that the coating film was so thin that the coating was difficult to be formed on the steel substrate in the process of the thermal spraying.

\section{Corrosion products}

XRD spectrums of thermal spray coating Al-Mg using atmospheric exposure test simulating marine environment after one-year are shown in Figure 2. For the initial material of the sprayed coating, diffraction peaks of only $\mathrm{Al}$ and $\mathrm{Mg}$ were observed. This indicates that $\mathrm{Al}-\mathrm{Mg}$ compounds were not produced as component elements of the coating. For both the atmospheric exposure test and the atmospheric exposure test simulating marine environment, diffraction peaks of only $\mathrm{Al}$ and $\mathrm{Mg}$ were observed but corrosion products were not observed after the exposure tests. As described above, for both exposure tests, the corrosion products of $\mathrm{Al}-\mathrm{Mg}$ thermal spray could not be identified.

\section{Film thickness measurement of electric arc thermal spray Al-Mg coating}

Figure 3 shows the film thickness of electric arc thermal spray coatings $\mathrm{AlMg} 30$ and AlMg60, after one-year using atmospheric exposure test simulating marine environment. The average thickness of the AlMg30 initial material was about $47.8 \mu \mathrm{m}$ and the standard deviation of the coating surface was considerably large. After the one-year exposure test, the thickness decreased to about $17 \mu \mathrm{m}$ in the atmospheric exposure test. In the atmospheric exposure test simulating marine environment, the thickness decreased to $16 \mu \mathrm{m}$, which was comparable to that in the atmospheric exposure test. The effect of the artificial seawater sprayed on the material was not observed. The average thickness of the sprayed coating on AlMg60 initial material was about $79 \mu \mathrm{m}$. Although the thickness after the one-year atmospheric exposure test became about the same as that of the initial material, the thickness decreased to $55 \mathrm{~mm}$ after the atmospheric exposure test simulating marine environment. Thus, the effect of the artificial seawater spray was observed. 


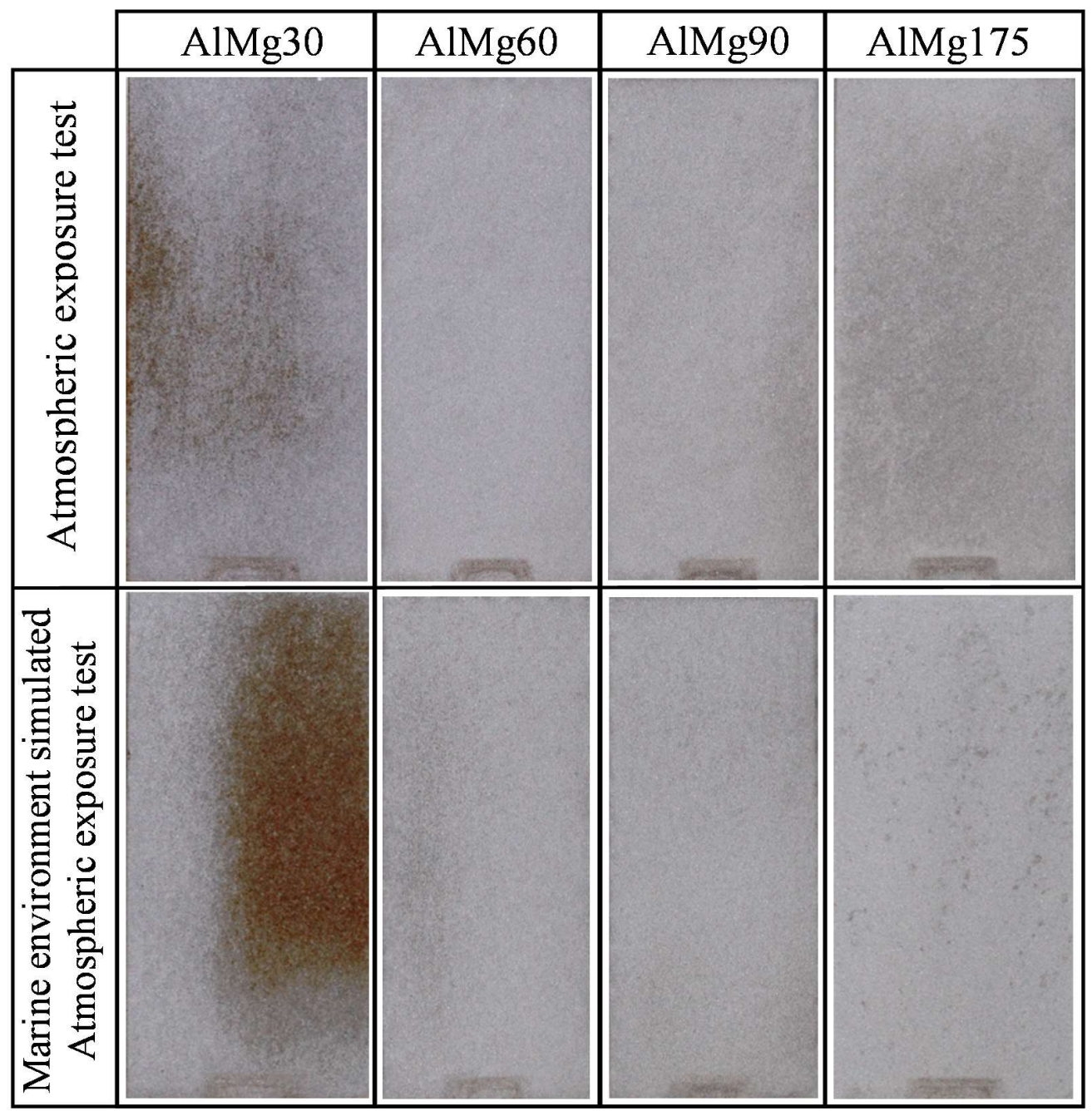

Figure 1 Surface appearance of AlMg30, AlMg60, AlMg90 and AlMg175 arc thermal spray coatings exposed for 1 year. 


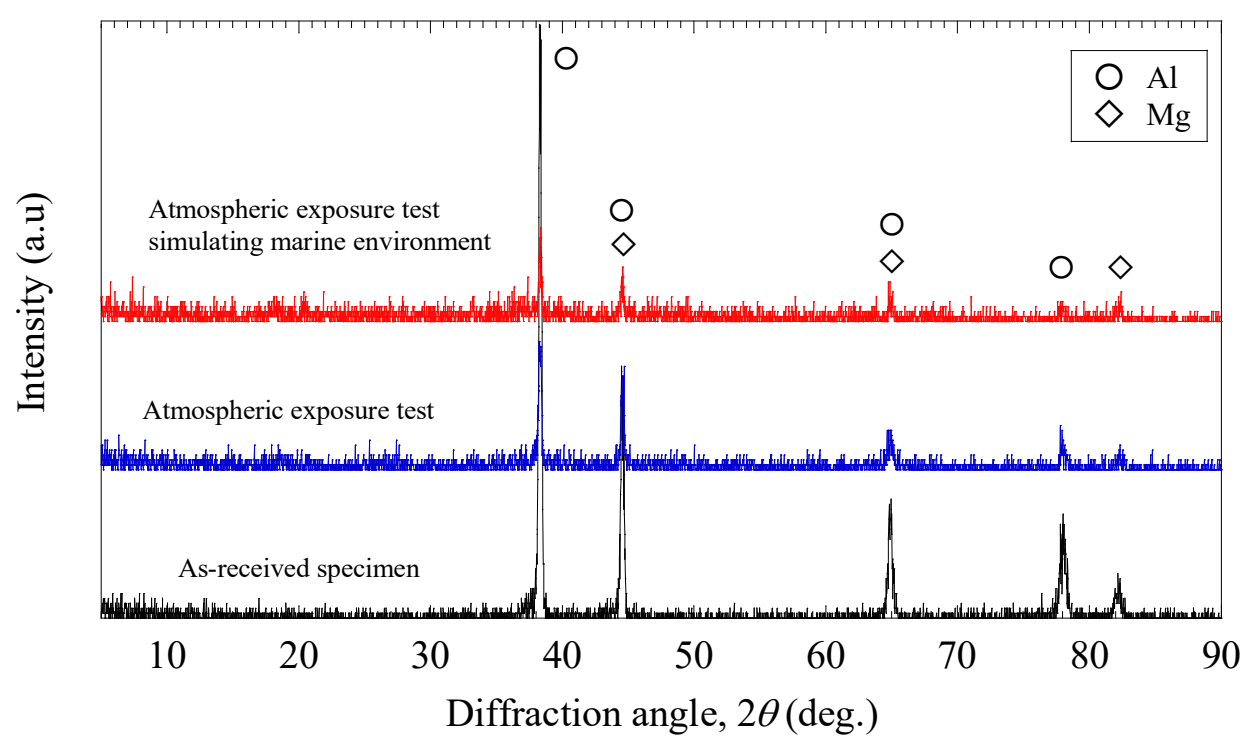

Figure $2 \mathrm{X}$-ray diffractograms of $\mathrm{Al}-5 \mathrm{mass} \% \mathrm{Mg}$ arc thermal spray coatings exposed for 1 year

Figure 4 shows the film thickness of electric arc thermal spray coatings AlMg90 and AlMg175, after one-year using atmospheric exposure test simulating marine environment. For initial materials of AlMg90 and AlMg175, the initial thickness was so large that the standard deviations became larger than those of the AlMg30 and AlMg60. The average thickness of the sprayed coating of theAlMg90 initial material was about $93 \mu \mathrm{m}$, Whereas the thickness became about the same as that of the initial material after the one-year atmospheric exposure test, it increased to $110 \mathrm{~mm}$ after the atmospheric exposure test simulating marine environment. Also in the case of Al-Mg175, whereas the average thickness of the sprayed coating became the same as that of the initial material after the one-year atmospheric exposure test, it increased after the atmospheric exposure test simulating marine environment.

As described above, when coating film was thin, the thickness of the sprayed coating decreased after one-year atmospheric exposure test. The reason seems to be that when the coating film is as thin as $30 \mu \mathrm{m}$, satisfactory coating is not formed because uniform thin film formation by thermal spraying on a steel substrate roughened by blasting is difficult as compared to the case of thick film formation. For that reason, it is considered that steel substrate was exposed in some parts of the coating surface and the thickness decreased because the internal corrosion proceeded at these parts. On the other hand, when the coating film was thick, it was observed that the average thickness increased by spraying artificial seawater. As to this result, the satisfactory corrosion resistance is expected considering that the film thicker than $90 \mu \mathrm{m}$ was formed. We consider that it will be necessary to continuously measure the changes in film thickness in the future. 


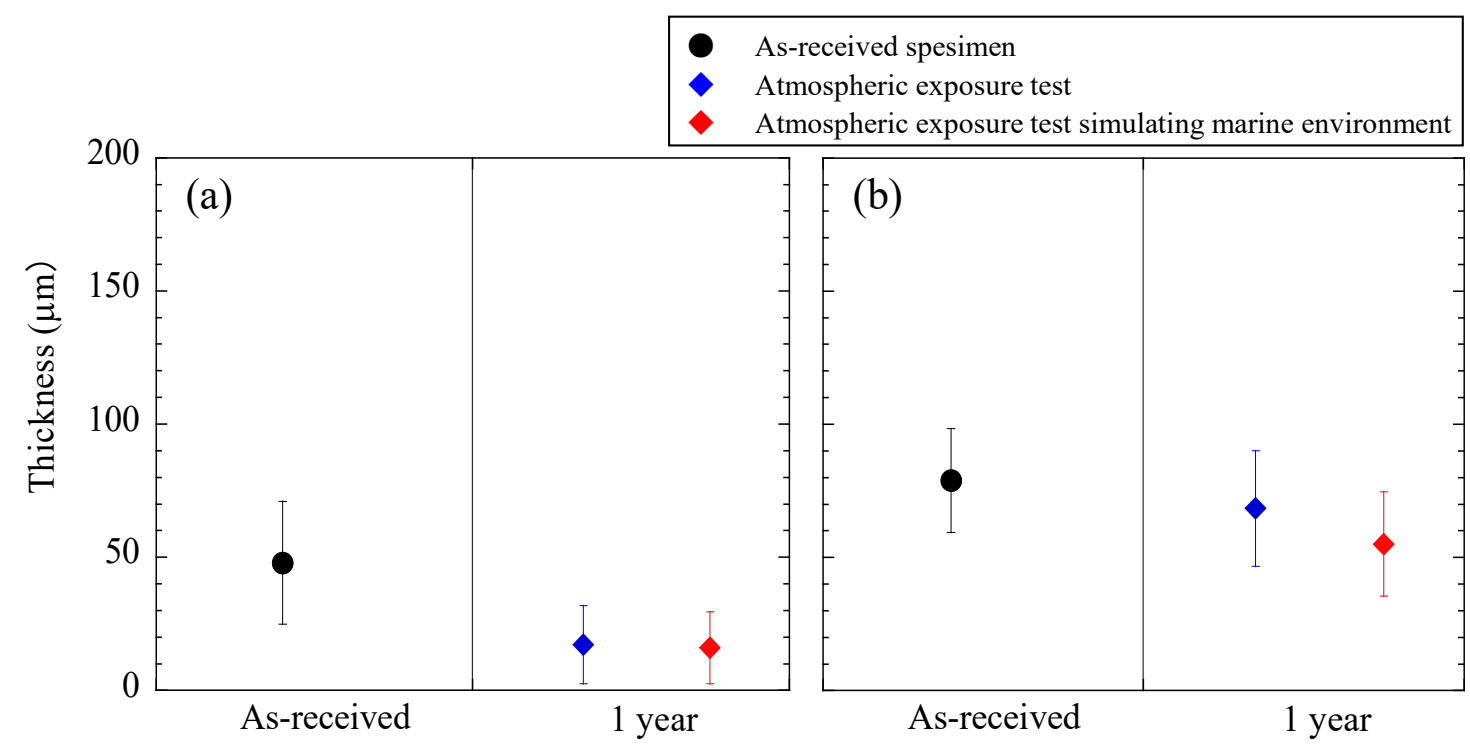

Figure 3 Coating thickness of (a) AlMg30, (b) AlMg60, after 1 year using atmospheric exposure test simulating marine environment.

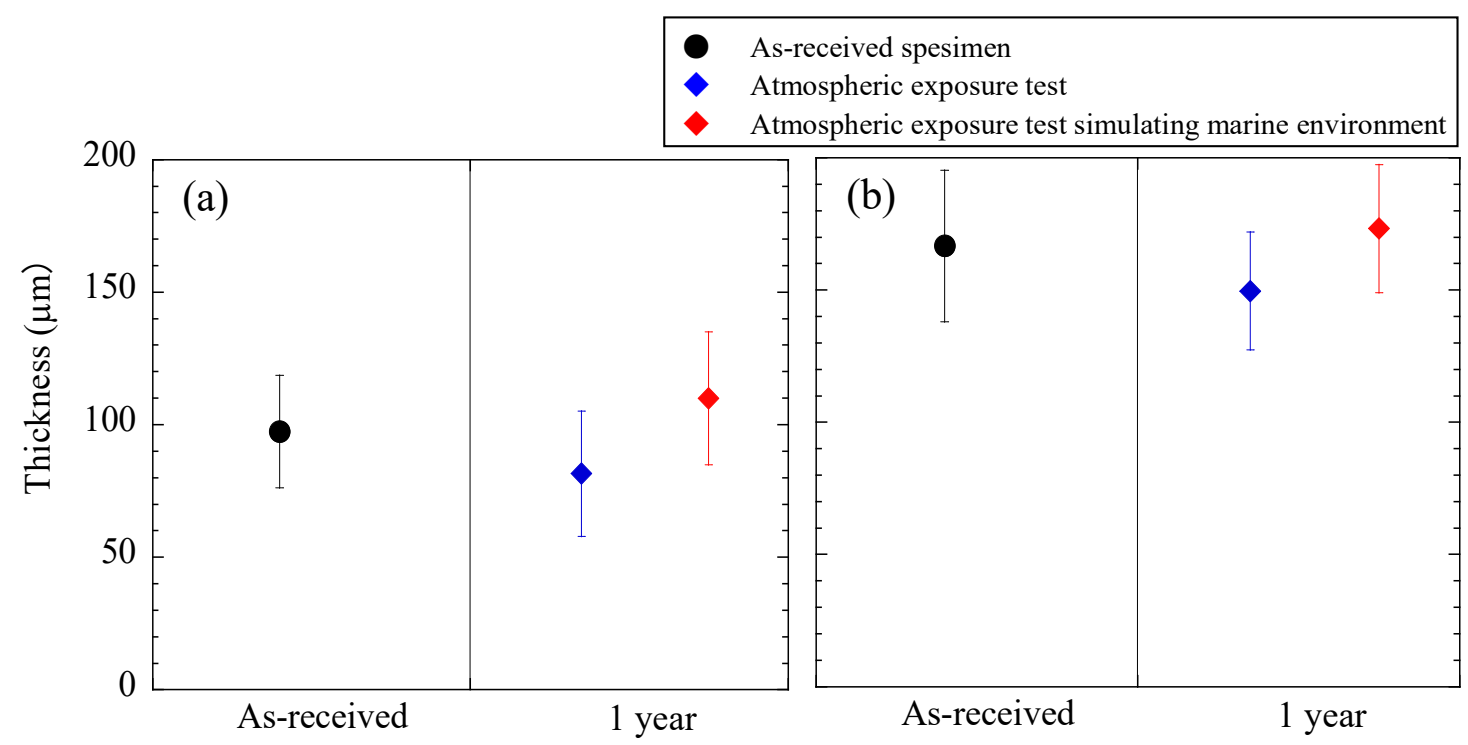

Figure 4 Coating thickness of (a) AlMg90, (b) AlMg175, after 1 year using atmospheric exposure test simulating marine environment. 


\section{SEM images and elemental distribution by EPMA}

Figure 5 shows the SEM images and EPMA elemental mapping for electric arc thermal spray coatings AlMg30 using atmospheric exposure test for one-year.

From the images observed by scanning electron microscope (SEM), it was found that Al-Mg thermal spray coating was formed on a steel substrate roughened by the blasting. The surface of the thermal spray coating was considerably rough, and defects like voids were observed in the coating film. In the coating film, the distribution of $\mathrm{Al}$ was the same as that of oxygen atoms, and they were homogenously distributed. $\mathrm{Mg}$ dissolved in $\mathrm{Al}$ and it was localized at the parts with high $\mathrm{Al}$ concentration. Because the content of $\mathrm{Mg}$ was extremely low, it is considered that the satisfactory Al-Mg thermal spray coating was not formed. The oxides of $\mathrm{Al}$ or $\mathrm{Mg}$ were not formed, and neither $\mathrm{Cl}$ nor $\mathrm{S}$ were detected at the surface or inside of the film. From these results, it was concluded that neither $\mathrm{Cl}$ originating from airborne salts nor $\mathrm{S}$ that is an environmental pollutant were not observed in general atmospheric exposure tests.

Figure 6 shows the SEM images and EPMA elemental mapping for electric arc thermal spray coatings AlMg30 using atmospheric exposure test simulating marine environment for one-year. From the observed SEM images, it was found that the thermal spray coating became considerably thin, and there were some parts where the thickness was only a few dozen micrometers. Al was detected in localized area and the distribution of $\mathrm{Al}$ and that of $\mathrm{Mg}$ overlapped partially. This means that the satisfactory $\mathrm{Al}-\mathrm{Mg}$ thermal spray coating film was not formed, as in the case of Figure 5. On the other hand, oxygen atoms were detected throughout the thermal spray coating, while neither $\mathrm{Cl}$ nor $\mathrm{S}$ were detected in the surface or inside of the thermal spray coating. These results showed that $\mathrm{Cl}$ originating from the artificial seawater was not observed in the atmospheric exposure test simulating marine environment. Also, $\mathrm{Cl}$ originating from airborne salts was not detected in the general atmospheric exposure test.

Figure 7 shows the SEM images and EPMA elemental mapping for electric arc thermal spray coatings AlMg60 using atmospheric exposure test for one-year. From the SEM images, it was observed that the surface of the thermal spray coating was considerably rough, and the number of voids inside the film was much larger than that of AlMg30 (Figure 5). Oxygen atoms were found to be distributed at the interface between the steel substrate and the thermal spray coating and inside of the film.

Figure 8 shows the SEM images and EPMA elemental mapping for electric arc thermal spray coatings AlMg60 using atmospheric exposure test simulating marine environment for one-year. From the images observed by SEM, the surface of the thermal spray coating was considerably rough, and defects like voids were observed in the coating film. It was observed that the coating film was thinner than that of AlMg60 (Figure 7) which was obtained by the general atmospheric exposure test. The distribution of Al was the same as that of oxygen atoms, and they were homogenously distributed. A large amount of oxygen was detected at the interface between the steel substrate and the thermal spray coating and around the voids inside the coating film. These oxygen atoms are considered to originate from oxides that were formed at the surface of $\mathrm{Al}$ and $\mathrm{Mg}$ microparticles in the thermal spray process. $\mathrm{Cl}$ and $\mathrm{S}$ were not detected in the surface or inside of the thermal spray coating. 

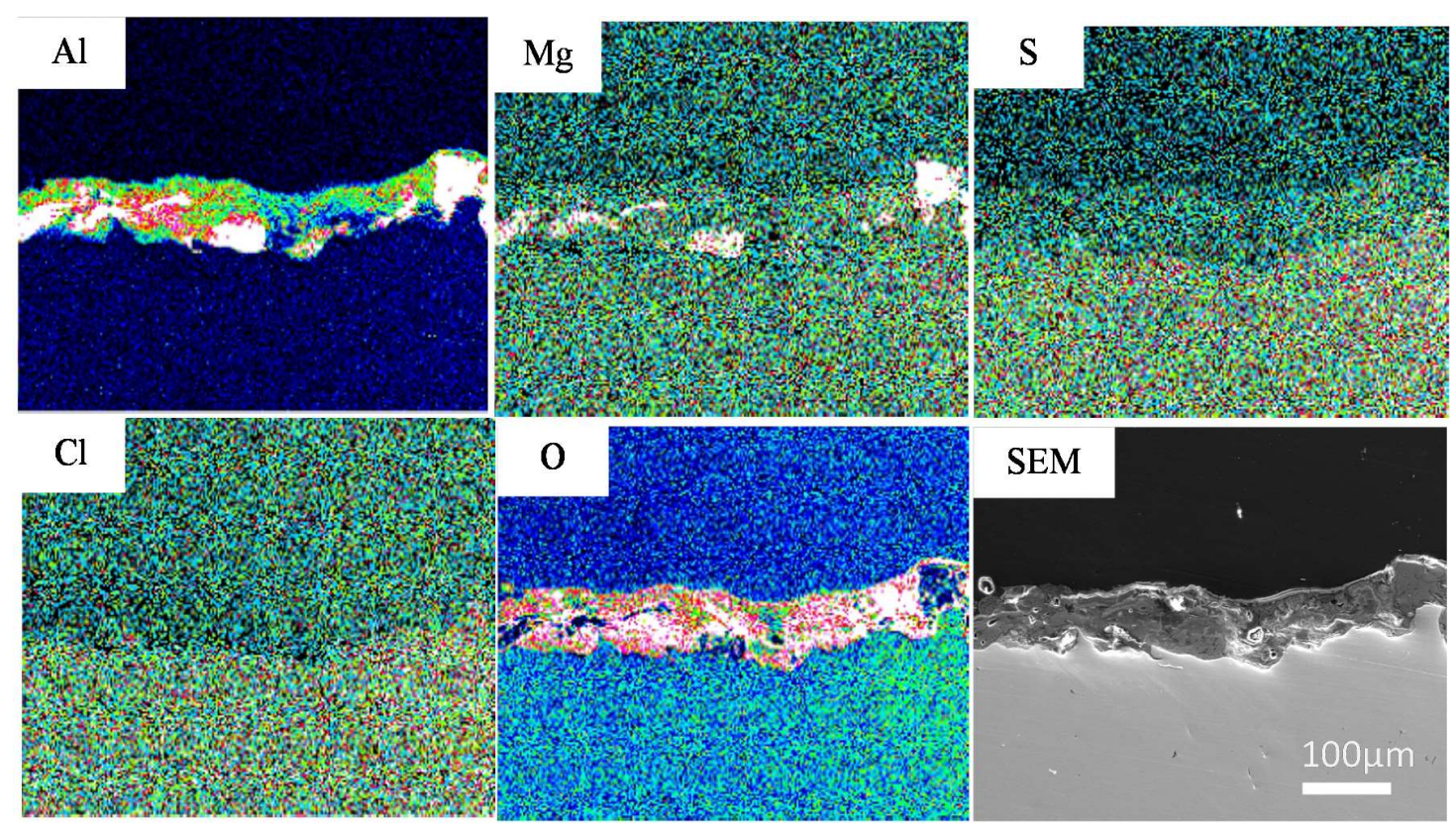

Figure 5 SEM image and EPMA elemental mapping for arc thermal sprayed AlMg30 coating after 1 year exposure using atmospheric exposure test.
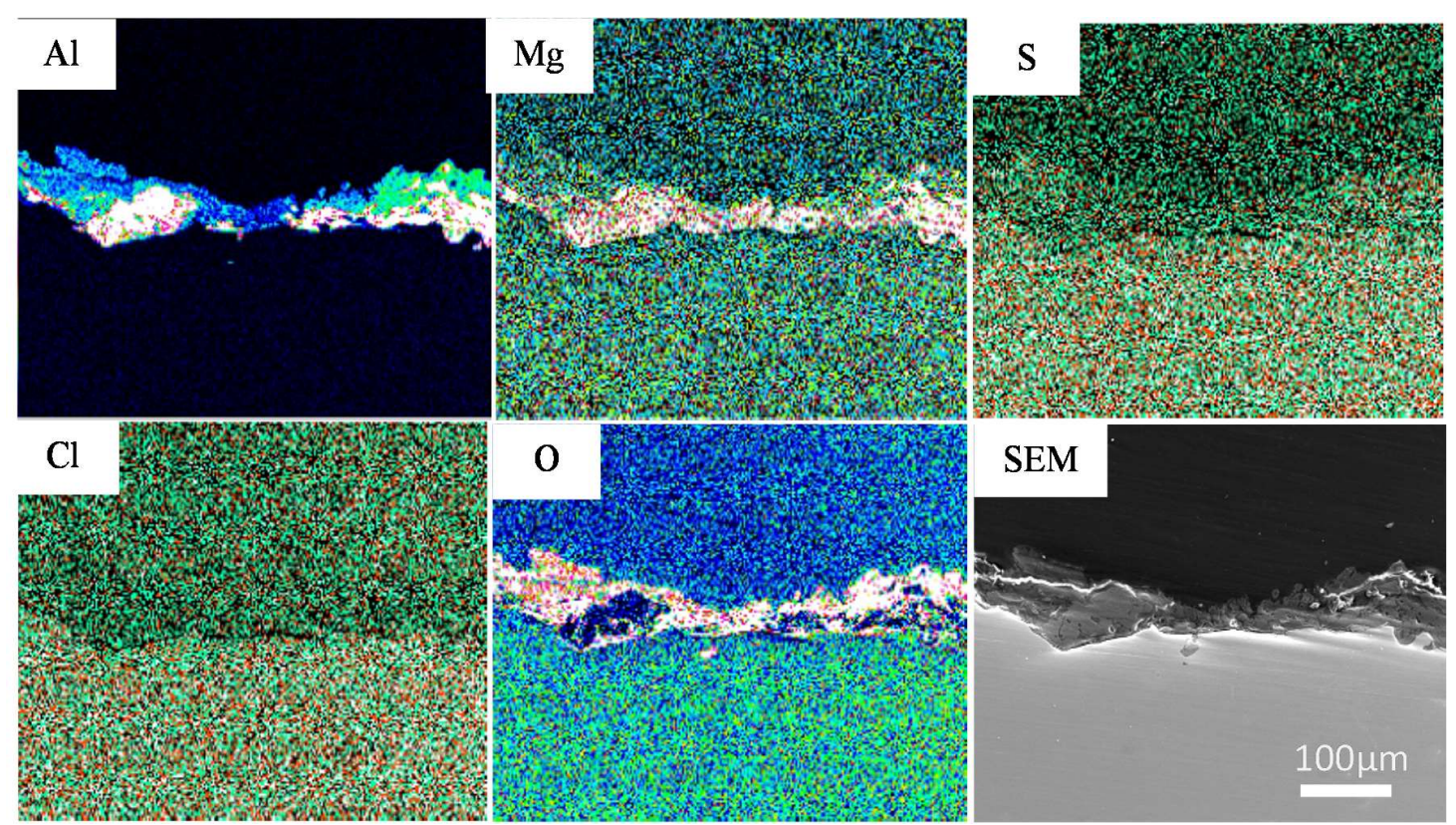

Figure 6 SEM image and EPMA elemental mapping for arc thermal sprayed AlMg30 coating after 1 year exposure using atmospheric exposure test simulating marine environment. 

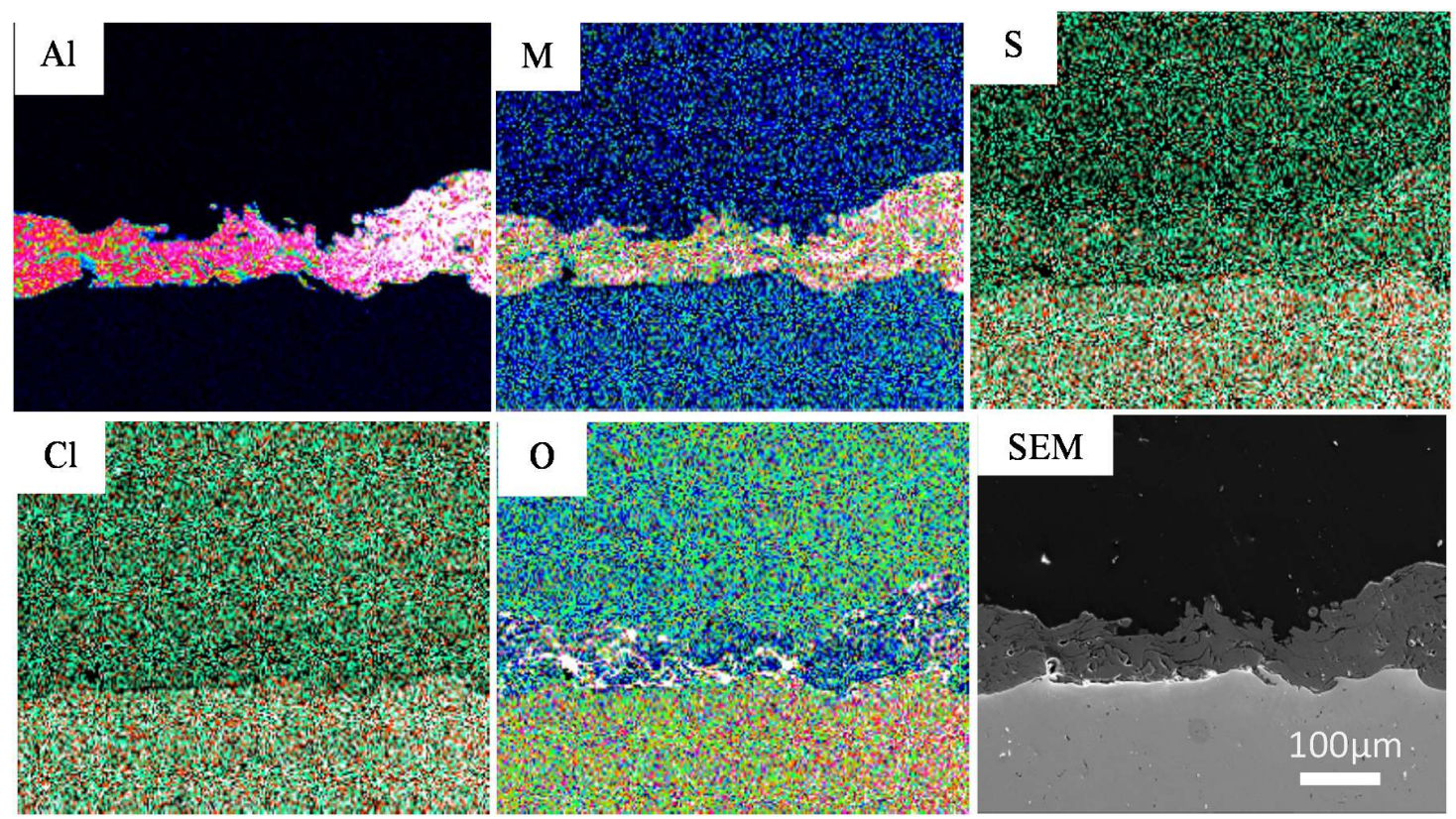

Figure 7 SEM image and EPMA elemental mapping for arc thermal sprayed AlMg60 coating after 1 year exposure using atmospheric exposure test.
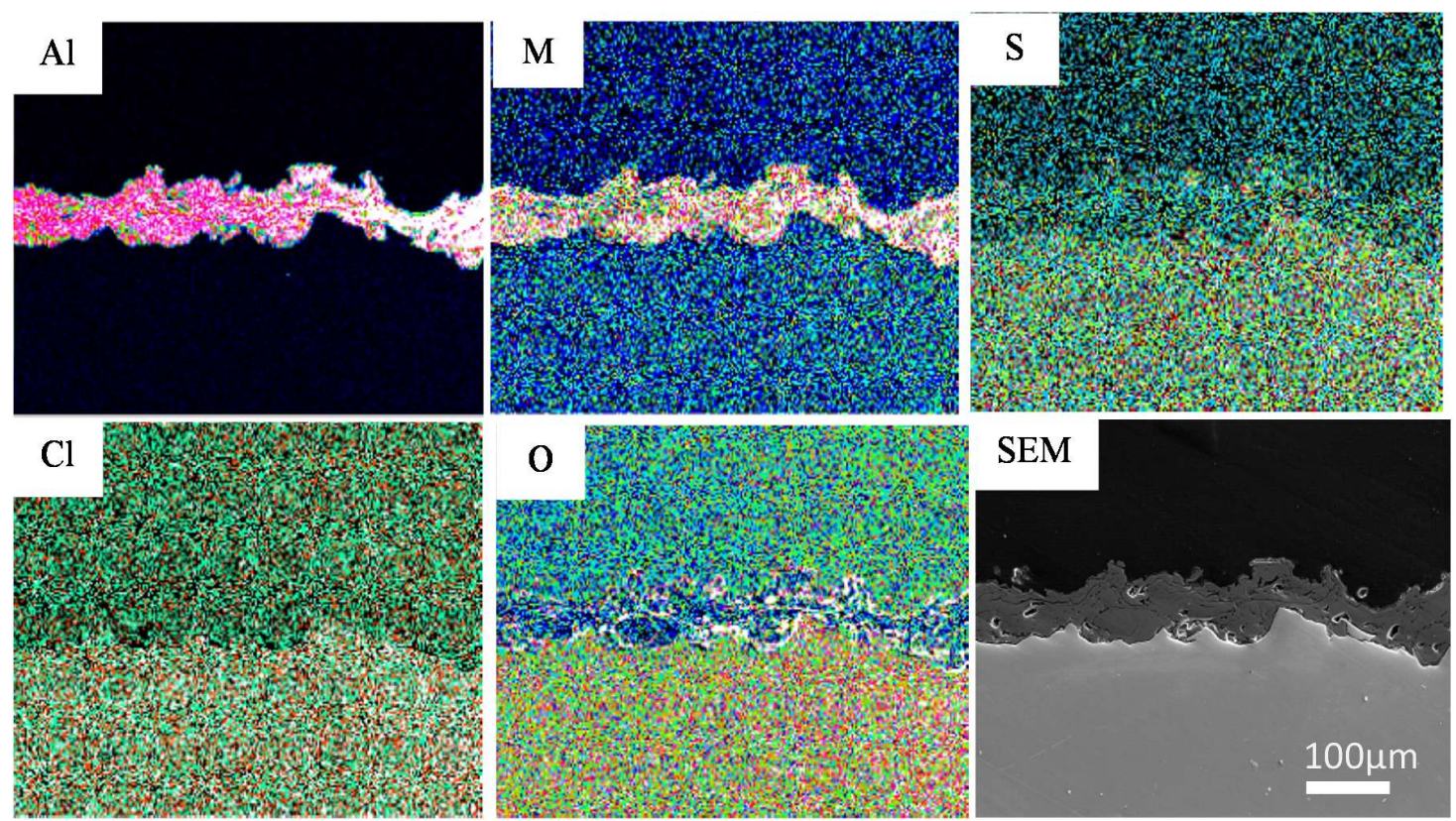

Figure 8 SEM image and EPMA elemental mapping for arc thermal sprayed AlMg60 coating after 1 year exposure using atmospheric exposure test simulating marine environment. 

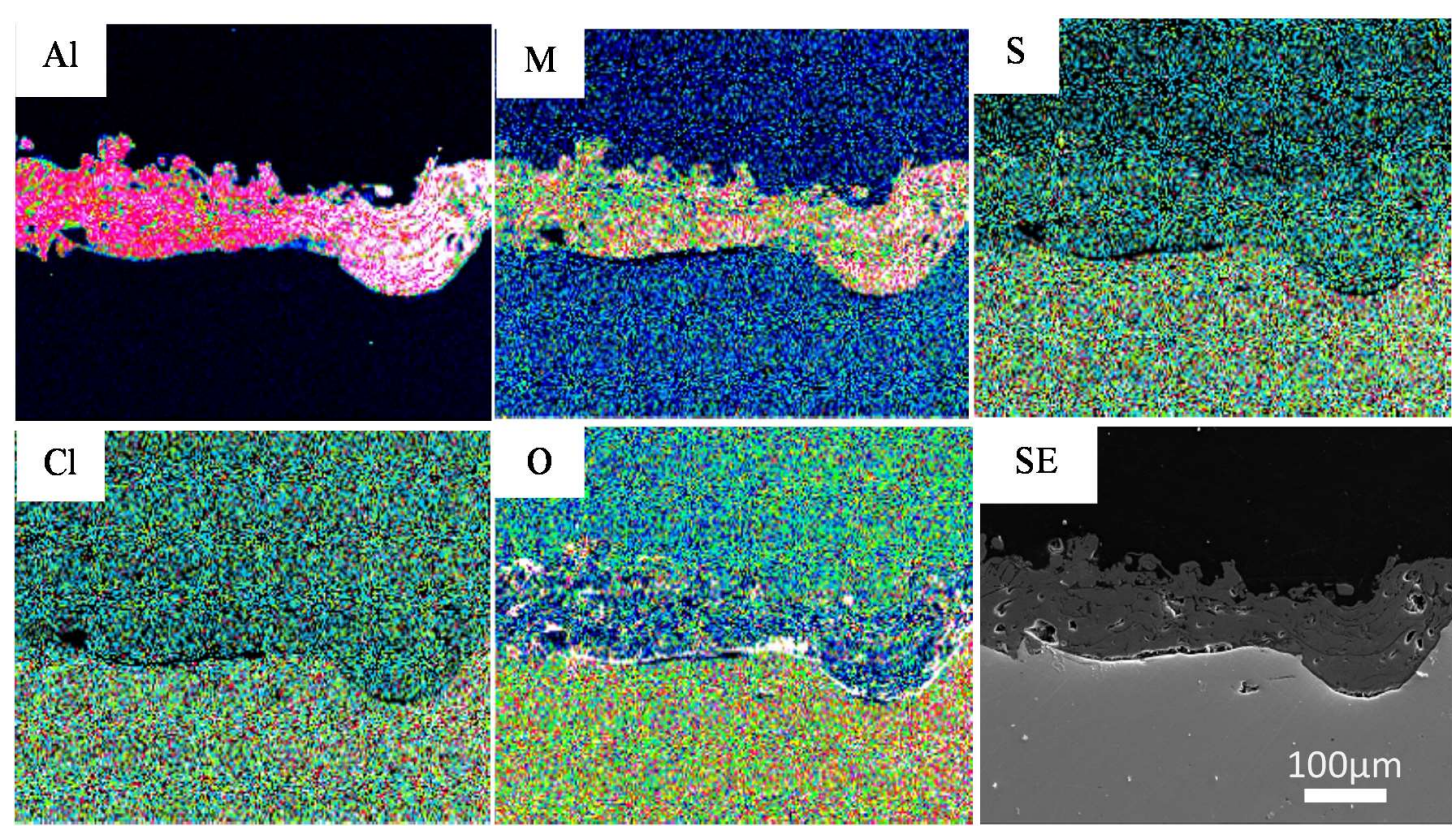

Figure 9 SEM image and EPMA elemental mapping for arc thermal sprayed AlMg90 coating after 1 year exposure using atmospheric exposure test.
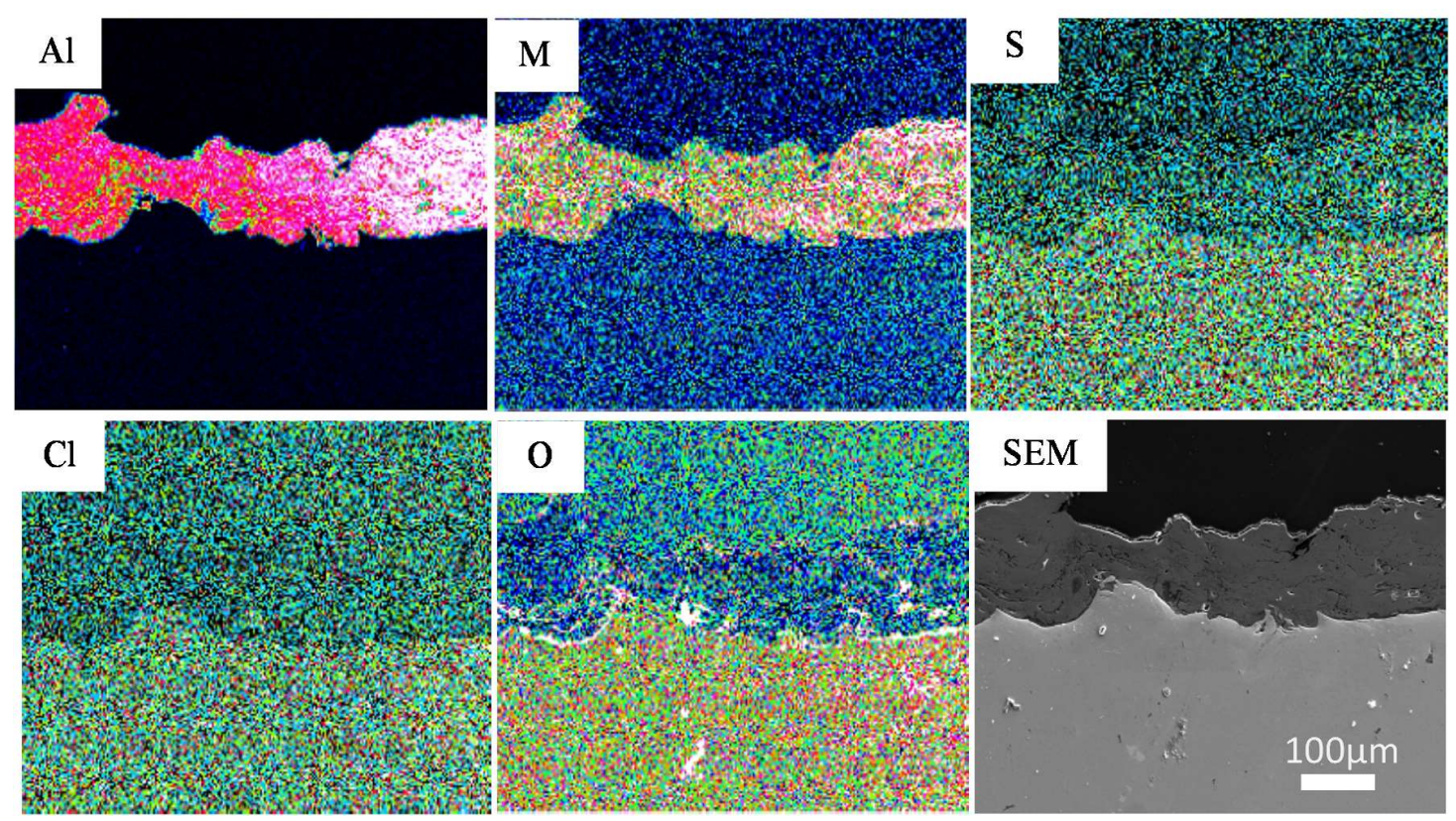

Figure 10 SEM image and EPMA elemental mapping for arc thermal sprayed AlMg90 coating after 1 year exposure using atmospheric exposure test simulating marine environment. 
Figure 9 shows the SEM images and EPMA elemental mapping for electric arc thermal spray coatings AlMg90 using atmospheric exposure test for one-year. The distribution of $\mathrm{Al}$ was the same as that of $\mathrm{Mg}$. The amount of oxygen at the interface between the steel substrate and the thermal spray coating was larger than that for AlMg60 (Figure 7). $\mathrm{Cl}$ and $\mathrm{S}$ were not detected in the surface or inside of the thermal spray coating.

Figure 10 shows the SEM images and EPMA elemental mapping for electric arc thermal spray coatings AlMg90 using atmospheric exposure test simulating marine environment for one-year. From the SEM images, it was observed that the surface of the coating film was considerably rough, and thickness of the film increased compared to the results obtained by the atmospheric exposure test (Figure 9)

\section{Electrochemical test}

The potentiodynamic polarization curves of specimens covered with $\mathrm{AlMg} 30$ (a) and AlMg90 (b) thermal spray coatings exposed for 1 year are given in Figure 11. The spontaneous potential of the AlMg30 initial material was about $-0.9 \mathrm{~V}_{\mathrm{SCE}}$, and it reached the diffusion-controlled current while the anode polarization curve exhibited the polarization. It should be noted that spontaneous potential of polished steel is generally $0.65 \sim-0.7 \mathrm{~V}_{\text {SCE }}$. Therefore, it is considered that Al-Mg thermal spray coating has substantial solubility as a sacrificial anode against steel, and its cathodic protection ability is sufficiently high.

The spontaneous potential of AlMg30 thermal spray coating after the one-year atmospheric exposure test shifted to the noble side compared to that of the initial material, and the value approached the spontaneous potential of steel. This means that when the thermal spray coating is thin like AlMg30, homogeneous film with enough thickness is difficult to be formed on a steel substrate. For this reason, the rusting started at the inhomogeneous parts of the film, which resulted in the exposure of the steel substrate. This process is considered to lead the results that the spontaneous potential of AlMg30 thermal spray coating became close to that of steel. The anode polarization after the atmospheric exposure test increased compared to that of the initial material. Especially, it increased in the atmospheric exposure test simulating marine environment.

When it comes to AlMg60, the spontaneous potential after the atmospheric exposure test shifted to the noble side from that of the initial material, which was the same as the $\mathrm{AlMg} 30$ results. The anode polarization for AlMg60 was gently polarized in both the general atmospheric exposure test and the atmospheric exposure test simulating marine environment, and the difference in values between two kinds of tests was considerably small.

The potentiodynamic polarization curves of specimens covered with AlMg175 (c) thermal spray coatings exposed for 1 year are given in Figure 12. In the case of $\mathrm{AlMg} 175$, the spontaneous potential after the atmospheric exposure test shifted to the noble side from that of the initial material, which was the same as the AlMg60 results. Here, it should be noted that when the coating film is thin (AlMg30), the spontaneous potential of the $\mathrm{Al}-\mathrm{Mg}$ thermal spray coating after the atmospheric exposure test was near that of steel, whereas the spontaneous potential became closer to that of the thermal spray coating of the initial material with the increase in the film thickness. In the anode polarization curve of AlMg175 after the atmospheric exposure test, the spray process exhibited the same polarization 

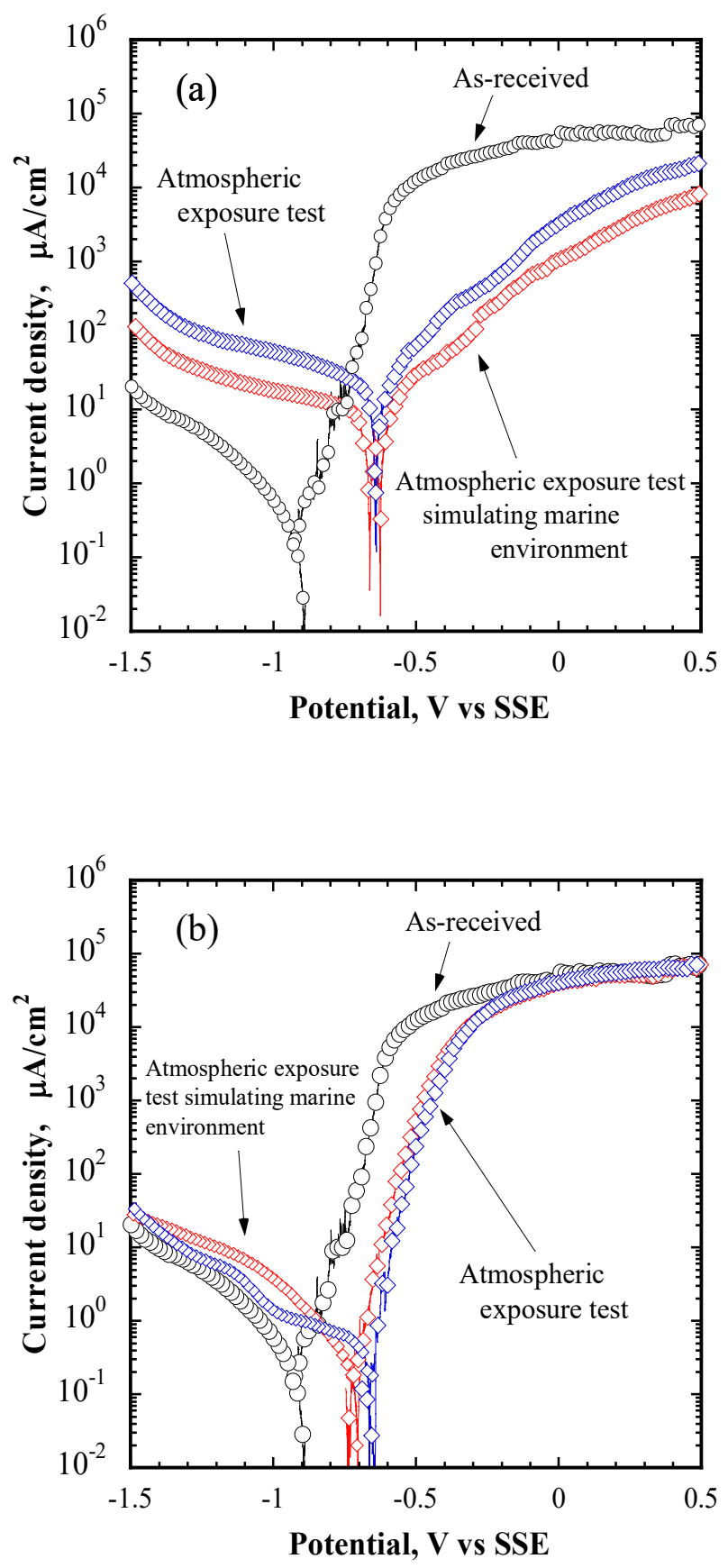

Figure 11 Polarization characteristics of (a) AlMg30, (b) AlMg90 thermal spray coatings exposed for 1 year. 


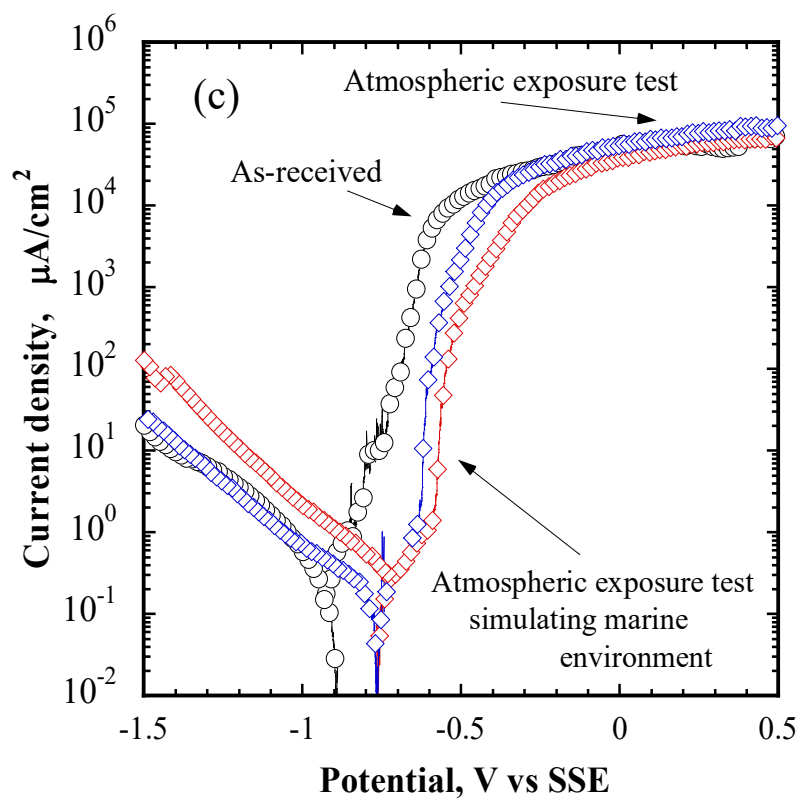

Figure 12 Polarization characteristics of (a) AlMg175, (b) AlMg90 thermal spray coatings exposed for 1 year.

behavior as that of the initial material, and it increase to the diffusion-controlled current while showing the anode polarization. Furthermore, it was observed that the anode polarization in the atmospheric exposure test simulating marine environment increased more than that in the general atmospheric exposure test. This result suggested the selfcorrosion suppression effect by the formation of the corrosion product layer.

\section{Conclusion}

A one-year atmospheric exposure test was conducted for steel with $\mathrm{Al}-5 \mathrm{wt} \% \mathrm{Mg}$ thermal sprayed steel using the atmospheric exposure test simulating marine environment. Atmospheric corrosion was evaluated by surface analysis, measurement of film thickness, EPMA cross-section analysis and electrochemical test. The results of the present study are presented below:

1. For AlMg30 with small film thickness, red rust was formed after the one-year atmospheric exposure test. In particular, red rust spread throughout the coating surface in the atmospheric exposure test simulating marine environment. When the film thickness became larger than $60 \mu \mathrm{m}$, no significant change was observed on the coating surface, which indicated the high corrosion resistance.

2. When the thickness of thermal spray coating of the initial material is small, the film thickness of Al-Mg thermal spray coating decreased. 
3. From the results of electron probe micro analyzer (EPMA) analysis, it was found that $\mathrm{Al}$ and $\mathrm{Mg}$ formed an alloy and oxygen atoms originating from oxides formed in the thermal spray process were detected. After the one-year atmospheric exposure test, $\mathrm{Cl}$ originating from airborne salts in atmosphere or from sprayed artificial seawater was not observed in the surface or inside of the Al-Mg thermal spray coating.

4. The spontaneous potential of Al-Mg thermal spray coating shifted to the noble side from that of the initial material after the one-year atmospheric exposure test. The anode polarization exhibited the same behavior in the two kinds of atmospheric exposure tests.

\section{Acknowledgments}

The authors would like to thank the DAIHEN Corporation for preparing the specimens used in this study.

\section{References}

1. Jian-hua Zhao, Yan-qingZhang, Surf. Coat. Technol. 307, p.301 (2016).

2. S. Natarajan, V. Sivan, Corrosion Prevention \& Control, 51, p.142 (2004).

3. C. Zhong, F. Liu, J. Alloys Compd., 520, p.11 (2012).

4. I.A. Kartsonakis, A.C. Balaskas, Corros. Sci., 65, p.11 (2012).

5. L. Zhu, G. Song, Surf. Coat. Technol., 200, p.2834 (2006).

6. M.C.L. de Oliveira, J.Mater.Eng Perform., 23, p. 593 (2014).

7. Y. Xiao, X. Jiang, Procedia Engineering, 27, pp. 1644 (2012).

8. Seiji Sugimura, Jinsun Liao, Surf. Coat. Technol. 302, p.398 (2016).

9. H. Katayama, S.Kuroda, Corrosion Science, 76, p.35 (2013).

10. H. Katayama, S.Kuroda, Bousei Kanri, 4, p.27 (2010).

11. M. Hachiya, Corros. Eng., 34, p. 635 (1985).

12. H. Y. Li, J.Y. Duan, Surf. Coat. Technol., 235, p. 259 (2013).

13. Q. Jiang, Q. Miao, Trans. Nonferrous Metals Soc. China, 24, p. 2713 (2014).

14. W. M. Zhao, Y. Wang, Surf. Coat. Technol., 205, p. 2267 (2010).

15. S.J. Kim, S.J. Lee, Trans. Nonferrous Metals Soc. China, 23, p. 1002 (2013).

16. M. Fukuda, K. Yokoyama, Structure Painting, 45, p.14 (2017)

17. K. Ozawa, Zairyo-to-Kankyo, 64(10), p.429 (2015). 